\title{
The Role of Red Cell Distribution Width as a Predictor of Bronchopulmonary Dysplasia in Preterm Infants
}

\section{Pelin Doğan}

Department of Pediatrics, Division of Neonatology, University of Health Sciences, Bursa Yuksek Ihtisas Teaching Hospital, Bursa, Turkey

\begin{abstract}
Introduction: Bronchopulmonary dysplasia (BPD) is one of the most frequent respiratory morbidity and the main cause of mortality in premature infants. This study aims to explore the role of red cell distribution width (RDW) to predict BPD in preterm infants.

Methods: Preterm infants of $\leq 32$ gestational weeks who were admitted to the neonatal intensive care unit during six months were enrolled in this retrospective study. The study cohort was divided into two groups according to BPD presence or not. Details of the demographic data of the patients and the laboratory data within three hours after birth were recorded. The relationship between RDW levels and BPD were evaluated.

Results: Seventy-eight infants were included in the final analysis. In the BPD group, gestational age and birth weight were significantly lower than the control group ( $p=0.001$ and $p=0.002$, respectively). In the BPD group, maternal preeclampsia was higher than the control group ( $p=0.04)$. In the BPD group, RDW levels were significantly higher than the control group $(p=0.002)$. After performing the multivariate model of logistic regression, significant predictors of BPD were RDW levels (OR= 11.986, 95\% Cl 2.494-57.602, $\mathrm{p}=0.002)$ and duration of invasive mechanical ventilation days (OR=1.429, 9\%5 Cl 1.127-1.811, $\mathrm{p}=0.003$ ). The optimal RDW cut point for prediction of BPD by the ROC curve analysis was $18 \%$, which yielded sensitivity $81.50 \%$ and specificity $84.78 \%$, and the AUC of RDW was $0.845(p<0.001)$.

Discussion and Conclusion: Our findings show that the RDW level is a significant parameter to predict BPD in preterm infants. RDW as a simple and accessible value may be of important role in the prediction and early approach of BPD in preterm infants. Keywords: Bronchopulmonary dysplasia; preterm; red cell distribution width.
\end{abstract}

W ith the advances in neonatology, the survival rates of preterm infants with very low birth weight have increased together with the incidence of chronic morbidities. The most important of these complications is bronchopulmonary dysplasia (BPD), which brings about important medical, familial, social and economic problems both during the neonatal intensive care unit stay and after discharge ${ }^{[1,2]}$. The incidence of BPD has markedly increased with decreased gestational week and low birth weight, and in preterm infants born below $1500 \mathrm{gr}$, BPD may have an incidence rate of $30-40 \%{ }^{[2,3]}$. Although many factors, such as immature lungs, barotrauma due to mechanical ventilation, oxidative stress and inflammation, lead to the development of BPD, especially inflammation plays a critical role in the pathogenesis of BPD ${ }^{[4,5]}$.

Erythrocyte distribution width (RDW) is a quantitative measure of variability in the size of circulating erythrocytes ${ }^{[6]}$. Any disease that induces erythrocyte production or de-

Correspondence (iletişim): Pelin Doğan, M.D. Bursa Yuksek Ihtisas Egitim ve Arastirma Hastanesi, Yildirim, 16120 Bursa, Turkey Phone (Telefon): +90 5053164268 E-mail (E-posta): pelin_akbas@yahoo.com 
struction may alter the size of the erythrocytes, causing a change in RDW. The systemic inflammatory response also affects erythrocyte destruction and erythropoiesis, and increased RDW values may indicate an underlying inflammatory reaction ${ }^{[7]}$. RDW is a marker that has been used in the meta-analysis for the follow-up of cardiac, renal, and pancreatic pathologies, especially in adults, and for the follow-up critical patients and predicting mortality ${ }^{[7-10]}$. In recent years, there are limited studies on the role of RDW in the follow-up of various diseases, such as patent ductus arteriosus (PDA), pulmonary hypertension and mortality in newborns with RDW $[6,11,12]$. The present study aims to investigate the role of RDW value in predicting BPD in preterm infants at birth.

\section{Materials and Methods}

Cases that were hospitalized at $\leq 32$ gestational weeks and treated for six months in the Neonatal Intensive Care Unit (NICU) of the University of Health Sciences, Bursa Yuksek Ihtisas Teaching Hospital, were included in this retrospective cohort study. The study group was divided into two groups as preterm infants who developed BPD or the control group that did not develop BPD during the follow-up period in NICU. Depending on the gestational age at birth, the definition of BPD was made as postmenstrual (PM) when BPD occurs at $36^{\text {th }}$ weeks for those with gestational week of $<32$ weeks, and $\mathrm{BPD}$ requiring $\geq 21 \mathrm{O}_{2}$. for those with gestational age of $\geq 32$ weeks when BPD emerges at postnatal $28^{\text {th }}$ day or earlier and persists at discharge time ${ }^{[13,14]}$.

Patients with moderate/severe maternal anemia, pregnant patients using drugs affecting fetal hematopoietic system, patients with a history of familial hematological disease, such as thalassemia, major congenital anemia, hydrops fetalis, patients undergoing intrauterine transfusion, patients whose maternal and neonatal data could not be reached and cases exited during follow-up period were excluded from this study. Data concerning maternal medical history, antenatal steroid use, early membrane rupture and/ or chorioamnionitis, maternal preeclampsia or infection, neonatal features including gestational age, birth weight, sex, mode of delivery, Apgar scores at $1^{\text {st }}$ and $5^{\text {th }}$ minutes, duration of invasive mechanical or non-invasive ventilation, oxygen use and hospitalization were recorded.

Within the first three hours after birth, $2 \mathrm{ml}$ samples of blood were drawn from peripheral veins of all patients included in this study and placed in the tube containing tripotassium ethylenediaminetetraacetic acid within the first three hours after birth, and blood count was performed within one hour after blood collection. Hematological parameters were defined by the Sysmex-XT-2000i blood counter (Sysmex, Kobe, Japan). Complete blood count parameters, including RDW of the blood samples of all patients, were recorded. BPD and control groups were compared concerning RDW and other complete blood count parameters.

\section{Statistical Analysis}

Statistical analysis was performed using IBM SPSS 20.0 (SPSS Inc., Chicago, IL, USA) statistical package program. The fitness to normal distribution was evaluated by the Kolmogorov-Smirnov Test. Numerical variables were given as mean $+/$ - standard deviation and median $\left(25^{\text {th }}\right.$ percentile to $75^{\text {th }}$ percentile). Categorical variables were expressed as numbers and percentages. Differences between the groups were evaluated with the Student t-test and one-way analysis of variance (ANOVA). Mann-Whitney U Test was used for numerical variables with non- normal distribution. Fisher's Exact and chi-square analyses were used for categorical variables. Logistic regression analysis was performed to investigate the relationship between RDW and BPD and factors affecting BPD were added to the model. ROC analysis was performed to evaluate the predictive power of different values. P-value of $<0.05$ was considered statistically significant.

\section{Results}

During the six-month period, 232 premature infants aged $\leq 32$ gestational weeks were hospitalized in the NICU, and 78 of these patients were included in this study according to exclusion criteria. When the neonatal and maternal demographic data of the study group were evaluated, it was observed that gestational week and birth weight rates were significantly lower in the BPD group compared to the control group ( $p=0.001$, and $p=0.002$, respectively). In addition, the rate of maternal preeclampsia was significantly higher in the BPD group than in the control group $(p=0.04)$. The maternal and neonatal demographic data of the study groups are summarized in Table 1. When the complete blood count parameters of the study groups were evaluated, the RDW values in the BPD group were significantly higher than the control group ( $p=0.002)$.

There was no significant difference between the two groups concerning other complete blood count parameters. Complete blood count parameters of the study groups are summarized in Table 2 . When other variables affecting the development of BPD were included in the multivariate logistic regression analysis as gestational week, birth 
Table 1. Neonatal and maternal characteristics of the study groups

\begin{tabular}{|c|c|c|c|}
\hline & $\begin{array}{l}\text { BPD Group } \\
\qquad(n=32)\end{array}$ & $\begin{array}{l}\text { Control Group } \\
\qquad(n=46)\end{array}$ & $\mathbf{p}$ \\
\hline GW at birth & $28(26-29)$ & $29(28-32)$ & $0.001^{a}$ \\
\hline \multicolumn{4}{|l|}{ median (IQR) } \\
\hline Birth weight gr median (IQR) & 1027 (841-1199) & $1245(1008-1572)$ & $0.002^{\mathrm{a}}$ \\
\hline \multicolumn{4}{|l|}{ Gender, n (\%) } \\
\hline Male & $17(53)$ & $27(62)$ & $0.6^{b}$ \\
\hline Female & $15(47)$ & $19(38)$ & \\
\hline Cesarean section, n (\%) & $25(78)$ & $38(83)$ & $0.6^{b}$ \\
\hline \multicolumn{4}{|l|}{ APGAR score, median (IQR) } \\
\hline 1. minute & $7(5-8)$ & $6(4-7)$ & $0.1^{\mathrm{a}}$ \\
\hline 5. minute & $8(7-9)$ & $8(7-9)$ & $0.1^{\mathrm{a}}$ \\
\hline \multicolumn{4}{|l|}{ Antenatal steroid use, n (\%) } \\
\hline None & $19(60)$ & $17(37)$ & \\
\hline Single course & $11(34)$ & $24(52)$ & $0.1^{\mathrm{c}}$ \\
\hline Single repeat course & $2(6)$ & $5(11)$ & \\
\hline Maternal preeclampsia, n (\%) & $11(34)$ & $7(15)$ & $0.04^{b}$ \\
\hline Maternal infection, n (\%) & $2(6)$ & $3(7)$ & $1.0^{c}$ \\
\hline PROM, n (\%) & $6(19)$ & $5(11)$ & $0.3^{c}$ \\
\hline Chorioamnionitis n (\%) & $2(6)$ & $3(7)$ & $1.0^{c}$ \\
\hline
\end{tabular}

Table 2. Laboratory findings of the study groups

\begin{tabular}{|c|c|c|c|}
\hline & $\begin{array}{l}\text { BPD Group } \\
\quad(n=32)\end{array}$ & $\begin{array}{l}\text { Control Group } \\
(n=46)\end{array}$ & $\mathbf{p}$ \\
\hline WBC $(103 / \mu \mathrm{L})$ median (IQR) & $9.6(5.5-13.7)$ & $10.6(5.8-13.6)$ & $0.4^{\mathrm{a}}$ \\
\hline Red blood cell count $(106 / \mu \mathrm{L})$, mean \pm SD & $4.4 \pm 0.6$ & $4.6 \pm 0.7$ & $0.2^{b}$ \\
\hline Hemoglobin (g/dl), mean \pm SD & $16.3 \pm 2.3$ & $17.4 \pm 2.7$ & $0.07^{b}$ \\
\hline Hematocrit (\%), mean \pm SD & $49.4 \pm 7.5$ & $52.5 \pm 8.1$ & $0.1^{b}$ \\
\hline Platelet count $\left(10^{3} / \mu \mathrm{L}\right)$, mean $\pm \mathrm{SD}$ & $205.8 \pm 67$ & $220.6 \pm 84.3$ & $0.4^{b}$ \\
\hline MPV (fL) median (IQR) & $8.2(7.6-9.4)$ & $8(7.4-8.7)$ & $0.2^{\mathrm{a}}$ \\
\hline $\mathrm{RDW}(\%)$, mean $\pm \mathrm{SD}$ & $18.6 \pm 0.7$ & $17.5 \pm 0.7$ & $<0.001^{b}$ \\
\hline
\end{tabular}

weight, invasive mechanical ventilation time, and RDW level $(\mathrm{OR}=11.986,95 \% \mathrm{Cl} 2.494-57.602, \mathrm{p}=0.002)$, invasive mechanical ventilation time $(\mathrm{OR}=1.429,95 \% \mathrm{Cl} 1.127-$ $1.811, \mathrm{p}=0.003$ ) was observed to be a significant predictor of BPD. When the ROC analysis was performed for the role of RDW in predicting the development of BPD, the cut-off value was determined as $18 \%$ with a sensitivity, specificity, and AUC value of $81.5 \%, 84.78 \%$ and 0.845 , respectively $(p<0.001)$ (Fig. 1).

\section{Discussion}

In recent years, due to advances in neonatology, especially in preterm infants, viability rates have increased despite low gestational weeks and birth weights, which has brought with it an increased incidence of morbidities, such as BPD [4]. Therefore, early detection of premature infants, which may be riskier for BPD, has become very important for clinicians, so clinical investigations have been conducted in recent years with many costly and difficult to access markers 


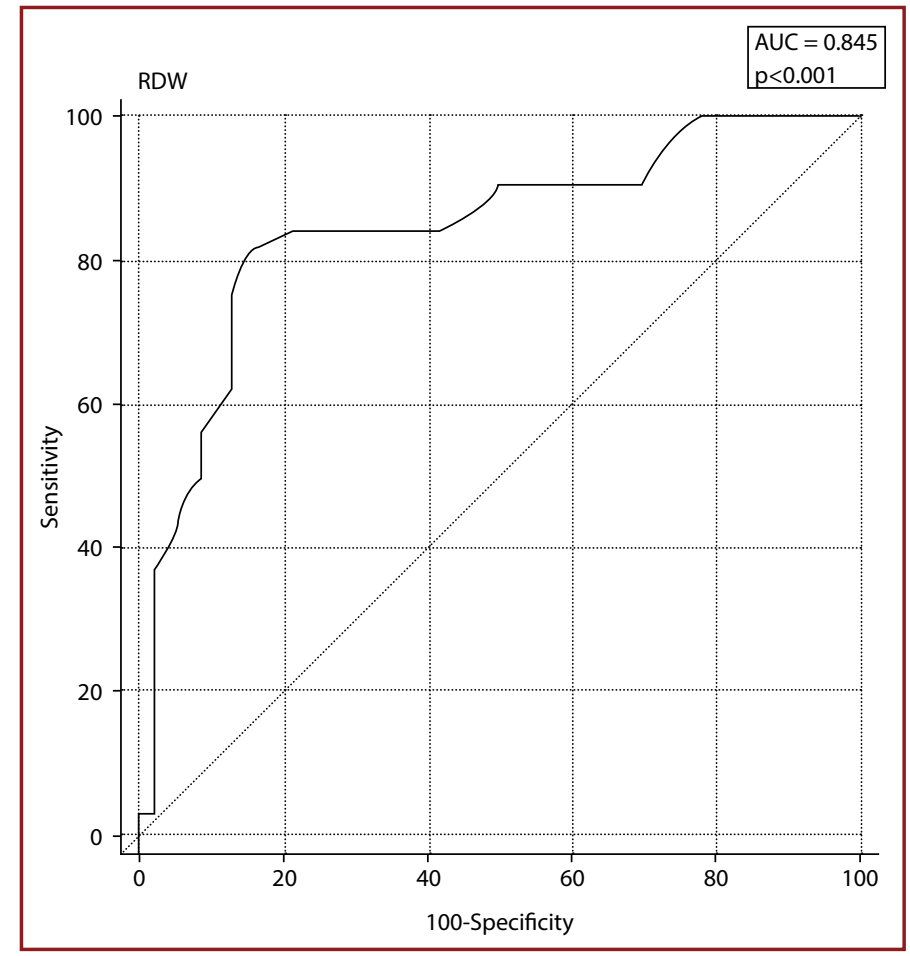

Figure 1. ROC analysis for the role of erythrocyte distribution width (RDW) in predicting bronchopulmonary dysplasia.

[15-17]. In this study, we found that RDW value at birth is an important predictor of BPD, and RDW value above $18 \%$ is a reliable threshold for predicting the development of BPD. In this study, it has been observed that the RDW value, which is practically accessible from the routine complete blood count measured at birth, is an important marker that can be used to predict BPD and shed light on the clinician in patient follow-up.

For many years, RDW has been used to monitor many different clinical conditions in adults. Increased RDW has been associated with an increased risk of prognosis and mortality, particularly in cases of acute inflammation, such as coronary syndrome or in chronic inflammatory conditions such as malignancies ${ }^{[7,18]}$. As a mechanism of the increase in RDW value, it has been indicated that inflammatory cytokines inhibit erythrocyte maturation and induce the release of younger and larger reticulocytes into the circulation and thus alter the distribution of erythrocytes $[7,10$, ${ }^{18]}$. In recent years after trials realized in adult patients and older children, studies evaluating the relationship between RDW and morbidities and mortality in newborns have been performed $[6,11,12,19,20]$. A recent study has shown that patients with persistent pulmonary hypertension (PPHT) had a significant increase in RDW and that RDW could be an independent predictor of $\mathrm{PPHT}{ }^{[20]}$.
It has also been shown in a recent study that the RDW value of $20 \%$ or more in patients with neonatal sepsis is associated with mortality ${ }^{[6]}$. In another study, an association was found between the increase in RDW and intrauterine growth retardation in preterm infants, and in the same study, it was reported that preterm infants with BPD had an elevated RDW value ${ }^{[11]}$. In this present study, in accordance with the literature, the findings showed that preterm infants who developed BPD had a significant increase in RDW at birth.

It is now known that the pathogenesis of BPD is not only a result of exposure to postnatal oxygen and mechanical ventilation but that many prenatal and postnatal multifactorial causes are responsible for the pathogenesis of BPD [21]. Early detection of the risk of BPD is very important for neonatologists, and many studies have been carried out in the last decades $[15,21]$. Indeed, the population with a higher risk of developing BPD can be treated with preventive treatment strategies in the early stages of life. Early protective steroid treatment can be applied after the first seven days of life and within the first two weeks before the lungs enter the irreversible fibrotic period ${ }^{[21]}$.

Studies on stem cell therapy among regenerative therapies and inhaled budesonide, or budesonide-surfactant combinations that may be protective from BPD in the early stage of the disease are also promising ${ }^{[22]}$. Many studies have tried to determine the risky population for BPD by looking at the levels of many different inflammatory cytokines in the blood and tracheal aspirate. However, unfortunately, the desired results could not be obtained with a single marker or combination of markers examined ${ }^{[15]}$. In a recent study, it has been reported that the evaluation of echocardiography findings in the first week of life and the need for mechanical ventilation on the $7^{\text {th }}$ day of life can be used to predict BPD [21]. In this study, the threshold RDW value measured within the first three hours after birth was found to be $18 \%$, and RDW values above this value have been shown to be associated with the development of BPD.

The primary limitation of this study was the retrospective design of the study, which resulted in the difficulty of accessing reliable and high-quality data. Since the data of many patients were not fully available, the analysis was performed with relatively few cases. In this study, patients were analyzed only on a single RDW value after birth but could be evaluated and analyzed together with a different variable, such as the need for invasive mechanical ventilation on the $7^{\text {th }}$ day that affected the development of BPD.

As the strengths of this study, primarily, many patients who were thought to have a negative impact on the anal- 
ysis were excluded from this study according to exclusion criteria. Secondly, we should note that very few studies in the literature have drawn attention to the relationship between RDW and BPD in newborns, and this study may shed light on studies to be performed.

\section{Conclusion}

In conclusion, in this study, we have shown that we can predict the development of BPD, which is one of the most lifethreatening morbidities of preterm infants, with an easyto-reach and practical variable in hemogram parameters, such as RDW. We think that the relationship between RDW and BPD should be evaluated in prospective studies with larger patient groups.

Ethics Committee Approval: Retrospective study.

Peer-review: Externally peer-reviewed.

Conflict of Interest: None declared.

Financial Disclosure: The authors declared that this study received no financial support.

\section{References}

1. Bhandari A, Bhandari V. Bronchopulmonary dysplasia: an update. Indian J Pediatr 2007;74:73-7. [CrossRef]

2. Siffel C, Kistler KD, Lewis JFM, Sarda SP. Global incidence of bronchopulmonary dysplasia among extremely preterm infants: a systematic literature review. J Matern Fetal Neonatal Med 2019:1-11. [CrossRef]

3. Abounahia FF, Abu-Jarir R, Abounahia MF, Al-Badriyeh D, Abushanab D, Abu-Ghalwa M, et al. Prophylactic Sildenafil in Preterm Infants at Risk of Bronchopulmonary Dysplasia: A Pilot Randomized, Double-Blinded, Placebo-Controlled Trial. Clin Drug Investig 2019;39:1093-107. [CrossRef]

4. Zheng Y, Xiu W, Lin Y, Ren Y, Zhang B, Yang C. Long-term effects of the intratracheal administration of corticosteroids for the prevention of bronchopulmonary dysplasia: A meta-analysis. Pediatr Pulmonol 2019;54:1722-34. [CrossRef]

5. Bancalari E, Claure N, Sosenko IR. Bronchopulmonary dysplasia: changes in pathogenesis, epidemiology and definition. Semin Neonatol 2003;8:63-71. [CrossRef]

6. Martin SL, Desai S, Nanavati R, Colah RB, Ghosh K, Mukherjee MB. Red cell distribution width and its association with mortality in neonatal sepsis. J Matern Fetal Neonatal Med 2019;32:1925-30. [CrossRef]

7. Targoński R, Sadowski J, Starek-Stelmaszczyk M, Targoński R, Rynkiewicz A. Prognostic significance of red cell distribution width and its relation to increased pulmonary pressure and inflammation in acute heart failure. Cardiol J 2018.

8. Wang B, Lu H, Gong Y, Ying B, Cheng B. The Association be- tween Red Blood Cell Distribution Width and Mortality in Critically III Patients with Acute Kidney In jury. Biomed Res Int 2018;2018:9658216. [CrossRef]

9. Yılmaz EM, Kandemir A. Significance of red blood cell distribution width and $C$-reactive protein/albumin levels in predicting prognosis of acute pancreatitis. Ulus Travma Acil Cerrahi Derg 2018;24:528-31. [CrossRef]

10. Patel KV, Semba RD, Ferrucci L, Newman AB, Fried LP, Wallace $\mathrm{RB}$, et al. Red cell distribution width and mortality in older adults: a meta-analysis. J Gerontol A Biol Sci Med Sci 2010;65:258-65. [CrossRef]

11. Garofoli F, Ciardelli L, Mazzucchelli I, Borghesi A, Angelini M, Bollani $L$, et al. The red cell distribution width (RDW): value and role in preterm, IUGR (intrauterine growth restricted), fullterm infants. Hematology 2014;19:365-9. [CrossRef]

12. Özer Bekmez B, Tayman C, Büyüktiryaki M, Çetinkaya AK, Çakır $U$, Derme T. A promising, novel index in the diagnosis and follow-up of patent ductus arteriosus: Red cell distribution width-to-platelet ratio. J Clin Lab Anal 2018;32:e22616.

13. Jobe AH, Bancalari E. Bronchopulmonary dysplasia. Am J Respir Crit Care Med 2001;163:1723-9. [CrossRef]

14. Bancalari $\mathrm{EH}$, Jobe $\mathrm{AH}$. The respiratory course of extremely preterm infants: a dilemma for diagnosis and terminology. J Pediatr 2012;161:585-8. [CrossRef]

15. Philpot PA, Bhandari V. Predicting the likelihood of bronchopulmonary dysplasia in premature neonates. Expert Rev Respir Med 2019;13:871-84. [CrossRef]

16. Kandasamy J, Roane C, Szalai A, Ambalavanan N. Serum eotaxin-1 is increased in extremely-low-birth-weight infants with bronchopulmonary dysplasia or death. Pediatr Res 2015;78:498-504. [CrossRef]

17. Bose C, Laughon M, Allred EN, Van Marter LJ, O'Shea TM, Ehrenkranz RA, et al. Blood protein concentrations in the first two postnatal weeks that predict bronchopulmonary dysplasia among infants born before the 28th week of gestation. Pediatr Res 2011;69:347-53. [CrossRef]

18. Ge W, Xie J, Chang L. Elevated red blood cell distribution width predicts poor prognosis in patients with oral squamous cell carcinoma. Cancer Manag Res 2018;10:3611-8. [CrossRef]

19. Kim SY, Lee SM, Sung SJ, Han SJ, Kim BJ, Park CW, et al. Red cell distribution width as a potential prognostic biomarker in fetal growth restriction. J Matern Fetal Neonatal Med 2019:1-6.

20. Sagheb S, Sepidarkish M, Mohseni SO, Movahedian A, Mosayebi Z. Red Cell Distribution Width as a Predictor of Persistent Pulmonary Hypertension of the Newborn. Am J Perinatol 2017;34:1442-6. [CrossRef]

21. Alvarez-Fuente M, Moreno L, Lopez-Ortego P, Arruza L, Avila-Alvarez A, Muro $M$, et al. Exploring clinical, echocardiographic and molecular biomarkers to predict bronchopulmonary dysplasia. PLoS One 2019;14:e0213210. [CrossRef]

22. Strueby L, Thebaud B. Novel therapeutics for bronchopulmonary dysplasia. Curr Opin Pediatr 2018;30:378-83. [CrossRef] 